\title{
Trajectories of PTSD Among Lower Manhattan Residents and Area Workers Following the 2001 World Trade Center Disaster, 2003-2012
}

\author{
Alice E. Welch, ${ }^{1}$ Kimberly Caramanica, ${ }^{1}$ Carey B. Maslow, ${ }^{1}$ Robert M. Brackbill, ${ }^{1}$ Steven D. Stellman, ${ }^{1,2}$ \\ and Mark R. Farfel ${ }^{1}$ \\ ${ }^{1}$ New York City Department of Health and Mental Hygiene, Queens, New York, USA \\ ${ }^{2}$ Department of Epidemiology, Mailman School of Public Health, Columbia University, New York, New York, USA
}

\begin{abstract}
Group-based trajectory modeling was used to explore empirical trajectories of symptoms of posttraumatic stress disorder (PTSD) among 17,062 adult area residents/workers (nonrescue/recovery workers) enrolled in the World Trade Center (WTC) Health Registry using 3 administrations of the PTSD Checklist (PCL) over 9 years of observation. Six trajectories described PTSD over time: low-stable $(48.9 \%)$, moderate-stable (28.3\%), moderate-increasing $(8.2 \%)$, high-stable $(6.0 \%)$, high-decreasing $(6.6 \%)$, and very high-stable $(2.0 \%)$. To examine factors associated with improving or worsening PTSD symptoms, groups with similar intercepts, but different trajectories were compared using bivariate analyses and logistic regression. The adjusted odds of being in the moderate-increasing relative to the moderate-stable group were significantly greater among enrollees reporting low social integration $(O R=2.18)$, WTC exposures $($ range $=$ 1.34 to 1.53$)$, job loss related to the September 11, 2001 disaster $(O R=1.41)$, or unmet mental health need/treatment $(O R=4.37)$. The odds of being in the high-stable relative to the high-decreasing group were significantly greater among enrollees reporting low social integration $(O R=2.23)$, WTC exposures (range $=1.39$ to 1.45$)$, or unmet mental health need/treatment $(O R=3.42)$. The influence of severe exposures, scarce personal/financial resources, and treatment barriers on PTSD trajectories suggest a need for early and ongoing PTSD screening postdisaster.
\end{abstract}

Posttraumatic stress disorder (PTSD) is one of the most common mental health sequelae of the September 11, 2001 (9/11) terrorist attacks on the World Trade Center (WTC) in New York City (NYC; Perlman et al., 2011). Lower Manhattan residents, area workers, and passersby who did not participate in 9/11-related rescue, recovery, or cleanup work (hereafter, area residents/workers) were nevertheless exposed to myriad physical and psychological hazards of varied intensity and duration in their homes and workplaces on 9/11 and for weeks and months

This study was supported by Cooperative Agreement Numbers 5U50/ OH009739 and 1E11/OH009630 from the National Institute for Occupational Safety and Health (NIOSH) of the Centers for Disease Control and Prevention (CDC); U50/ATU272750 from the Agency for Toxic Substances and Disease Registry (ATSDR), CDC, which included support from the National Center for Environmental Health, CDC; and by the New York City Department of Health and Mental Hygiene. Its contents are solely the responsibility of the authors and do not necessarily represent the official views of NIOSH-CDC. We are thankful to Drs. Howard Alper, Charon Gwynn, and Jim Hadler for their critical review of the manuscript.

Correspondence concerning this article should be addressed to Alice E. Welch, NYC Department of Health and Mental Hygiene, 42-09 28 Street, 07-24, Queens, NY 11101. E-mail: awelch1@ health.nyc.gov

Copyright (c) 2016 International Society for Traumatic Stress Studies. View this article online at wileyonlinelibrary.com

DOI: $10.1002 /$ jts. 22090 thereafter. This group accounts for more than three fourths of the estimated 409,000 persons with firsthand exposure to the attacks (Murphy et al., 2007).

Although a number of cross-sectional studies exist on post9/11 PTSD, relatively few studies have examined patterns of development of PTSD among area workers/residents. The WTC Health Registry (Registry) examined PTSD among a cohort of persons with direct 9/11 exposure on two occasions and found area residents/workers reported symptoms consistent with chronic (10.4\%) and late-onset (8.4\%) PTSD (Brackbill et al., 2009). Other studies examined 9/11-related PTSD on two occasions among broad-based samples of NYC residents (Adams \& Boscarino, 2006; Boscarino \& Adams, 2009; Neria et al., 2010) and more than two occasions (Galea et al., 2008).

Research on the trajectory of PTSD over time among trauma exposed groups using latent class growth modeling (Nagin, 2005) is emerging. WTC-related studies using group-based trajectory models have been conducted among those who participated in WTC rescue, recovery, and cleanup work (RRW; Maslow et al., 2015; Pietrzak et al., 2014) and a sample of NYC metropolitan area residents post-9/11 (Norris, Tracy, \& Galea, 2009). Other trajectory studies have evaluated PTSD among assault survivors (Steenkamp, Dickstein, Salters-Pedneault, Hofmann, \& Litz, 2012), persons experiencing traumatic injury 
(deRoon-Cassini, Mancini, Rusch, \& Bonanno, 2010), political violence (Hobfoll, Mancini, Hall, Canetti, \& Bonanno, 2011), natural disasters (Norris et al., 2009), and veterans (Bonanno et al., 2012). Observation periods in these studies ranged from 4 months (Steenkamp et al., 2012) to 8 years (Maslow et al., 2015), with most reporting short observation periods (average of 3 years). Most of these studies identified between four and six PTSD trajectory groups that were categorized as chronic, delayed-onset, recovered, or resilient/resistant (Bonanno et al., 2012; de-Roon-Cassini et al., 2010; Pietrzak et al., 2014). The largest proportions (53\%-85\%) of individuals in most of the studies were in groups with consistently low PTSD symptomatology. In their studies of responders, both Pietrzak et al. (2014) and Maslow et al. (2015) found groups with similar intercepts and trajectories that diverged over the study period.

Data from the Registry provided an opportunity to examine the course of PTSD among a large sample of directly exposed area residents/workers more than 7 years post-9/11, a population, which to date remains unstudied. It is crucial to replicate the analyses conducted among responders in a civilian population to better understand the burden of PTSD more than a decade after $9 / 11$ for future disaster preparedness planning and response. The goals of the current study were to (a) describe the course of PTSD symptoms among area residents/workers by identifying groups defined by similar PTSD trajectories over three survey waves 10-11 years post-9/11; (b) identify sociodemographic factors, 9/11-related exposures, and other factors associated with PTSD trajectories that worsened or improved over time; and (c) examine the relationship between quality of life and PTSD trajectory.

\section{Method}

\section{Participants and Procedure}

The Registry is a cohort study of 71,431 individuals directly exposed to the 9/11 disaster. Details on Registry recruitment have been published elsewhere (Farfel et al., 2008; Murphy et al., 2007). Briefly, enrollees include rescue/recovery workers and volunteers, lower Manhattan residents/area workers, and passersby. There were two modes of enrollment into the Registry. List-identified enrollees $(30.4 \%)$ were recruited from lists provided by governmental agencies, organizations, and employers. Self-identified enrollees (69.6\%) contacted the Registry via phone or preregistered on a website. The Wave 1 (W1) survey (2003-2004) included 68,802 adult enrollees; the Wave 2 (W2) survey (2006-2007) was completed by 46,602 adults; and the Wave 3 (W3) survey (2011-2012) was completed by 43,134 adults. W1 surveys were completed by phone, whereas W2 and W3 were completed by phone, web, and mail (survey mode). The Registry protocol was approved by the institutional review boards of the Centers for Disease Control and Prevention and NYC Department of Health and Mental Hygiene.

Participants included 17,062 Registry enrollees who were age 18 years or older at $\mathrm{W} 1$, completed all three waves, and did not participate in 9/11-related rescue/recovery/cleanup work. Enrollees with incomplete information on the PTSD Checklist at any wave were excluded. Enrollees who did not complete all three survey waves were more likely to have had PTSD at W1 than those completing all three waves, $\chi^{2}=(1, N=36270)$ $=65.26, p<.001$. A description of our study population is provided in Table 1.

\section{Measures}

The severity of 9/11-related PTSD symptoms was assessed at each wave using the stressor-specific PTSD Checklist (PCL; Weathers, Litz, Herman, Huska, \& Keane, 1993), on which questions in the reexperiencing and avoidance/numbing domains were queried specific to $9 / 11$. The PCL is a selfreported, 17-item scale corresponding to criteria defined in the Diagnostic and Statistical Manual of Mental Disorders ( $4^{\text {th }}$ ed., text rev., DSM-IV-TR; American Psychiatric Association, 2000) in three symptom clusters: reexperiencing, avoidance, and hyperarousal (Blanchard, Jones-Alexander, Buckley, \& Forneris, 1996; Ventureyra, Yao, Cottraux, Note, \& DeMayGuillard, 2002). The degree to which each symptom bothered the enrollee in the prior 30 days was rated from $1=$ not at all to $5=$ extremely, and summed as a score ranging from 17 to 85 . A cutoff score of $\geq 44$ was used to indicate probable PTSD and has been used among civilians (sensitivity $=.94$, specificity $=$ .86 , diagnostic efficiency $=.90$; Blanchard et al., 1996).

We included the following demographic variables and other psychosocial factors associated with PTSD in the extant literature. Demographic characteristics collected at W1 included gender, age, race/ethnicity, education, household income, marital status, and employment status (Adams \& Boscarino, 2006; Brackbill et al., 2009; Maslow et al., 2015). Enrollees reporting a diagnosis of PTSD, another anxiety disorder, or depression prior to $9 / 11$ on the W2 survey were considered to have a pre9/11 mental health diagnosis. Enrollees reporting one or no sources of social integration (at least one close friend, interacting with friends at least twice per month, attending religious services at least twice per month, or being actively involved in a club or organization) at W2 were considered to have low social integration.

Subjective unmet mental health care need (UMHN) at W2 was defined as a self-report of needing "mental healthcare or counseling" in the prior 12 months, but not receiving it. Any mental health treatment (MHT) at W2 was defined as a selfreport of any mental health counseling, medication use, or both in the prior 12 months. The two constructs were combined into an unmet need and mental health treatment composite variable with four categories: $\mathrm{UMHN}+/ \mathrm{MHT}+, \mathrm{UMHN}+/ \mathrm{MHT}-$, $\mathrm{UMHN}-/ \mathrm{MHT}+$, UMHN-/MHT-.

We examined $9 / 11$ exposures previously shown to be predictors of PTSD (Brackbill et al., 2009; DiGrande et al., 2008; Maslow et al., 2015; Perlman et al., 2011). Those exposures were: (a) 9/11-related job loss (b) witnessing three or more of the following events on 9/11 (seeing planes hit the 
Table 1

Description of the Area Residents/Workers Enrolled in the WTC Health Registry at Waves 1, 2, and 3

\begin{tabular}{|c|c|c|}
\hline Variable & $n$ & $\%$ \\
\hline \multicolumn{3}{|l|}{ Gender } \\
\hline Female & 9,023 & 52.9 \\
\hline Male & 8,039 & 47.1 \\
\hline \multicolumn{3}{|l|}{ Age at Wave 1} \\
\hline $18-24$ & 673 & 3.9 \\
\hline $25-44$ & 7,514 & 44.0 \\
\hline $45-64$ & 8,154 & 47.8 \\
\hline$\geq 65$ & 721 & 4.2 \\
\hline \multicolumn{3}{|l|}{ Race/ethnicity } \\
\hline Non-Hispanic White & 11,572 & 67.8 \\
\hline Non-Hispanic Black & 1,987 & 11.7 \\
\hline Hispanic & 1,774 & 10.4 \\
\hline Asian & 1,219 & 7.1 \\
\hline Multiracial/other & 510 & 3.0 \\
\hline \multicolumn{3}{|l|}{ Wave 1 household income } \\
\hline$\$ 24,999$ or less & 1,344 & 8.8 \\
\hline$\$ 25,000-\$ 49,999$ & 3,040 & 19.9 \\
\hline$\$ 50,000-\$ 74,999$ & 2,966 & 19.4 \\
\hline$\$ 75,000-\$ 99,999$ & 2,379 & 15.6 \\
\hline$\$ 100,000+$ & 5,543 & 36.3 \\
\hline \multicolumn{3}{|l|}{ Wave 1 college graduate } \\
\hline Yes & 11,262 & 66.2 \\
\hline No & 5,750 & 33.8 \\
\hline \multicolumn{3}{|l|}{ Wave 1 marital status } \\
\hline Married/living with partner & 10,365 & 61.0 \\
\hline Divorced/separated/widowed & 2,291 & 13.5 \\
\hline Never married & 4,327 & 25.5 \\
\hline \multicolumn{3}{|l|}{ Wave 1 employed } \\
\hline Yes & 14,716 & 86.3 \\
\hline No & 2,331 & 13.7 \\
\hline \multicolumn{3}{|l|}{ Wave 2 social integration } \\
\hline Low & 9,464 & 55.5 \\
\hline High & 7,590 & 44.5 \\
\hline \multicolumn{3}{|l|}{ Wave 2 unmet $\mathrm{MH}$ need, service use } \\
\hline UMHN+ MHT+ & 364 & 2.2 \\
\hline $\mathrm{UMHN}+\mathrm{MHT}-$ & 396 & 2.4 \\
\hline UMHN- MHT+ & 4,102 & 24.6 \\
\hline UMHN- MHT- & 11,842 & 70.9 \\
\hline \multicolumn{3}{|l|}{ Pre-9/11 mental health diagnosis } \\
\hline Yes & 2,021 & 12.4 \\
\hline No & 14,326 & 87.6 \\
\hline \multicolumn{3}{|l|}{ Wave 1 met criteria for full PTSD } \\
\hline Yes & 2,855 & 16.7 \\
\hline No & 14,207 & 83.3 \\
\hline
\end{tabular}

Note. $N=17,062$. WTC $=$ World Trade Center; UMHN $+=$ reported unmet mental healthcare need; $\mathrm{UMHN}-=$ did not report unmet mental healthcare need; $\mathrm{MHT}+=$ received mental health treatment; $\mathrm{MHT}-=$ did not receive mental health treatment.
WTC, buildings collapsing, people falling or jumping from buildings, people injured, or people running); (c) threat/fear of being injured or killed on 9/11; (d) having a relative, friend, and/or coworker killed on 9/11; and (e) sustaining an injury other than eye irritation/injury on $9 / 11$.

To assess the association between PTSD trajectory and quality of life, we included the following W3 self-rated measures: (a) general life satisfaction (very satisfied to very dissatisfied); (b) general health (excellent to poor); (c) number of poor mental health days in the last 30 days; (d) PTSD-related impairment (any impairment vs. no impairment); and (e) life stressors in the last 12 months. Life stressors included (a) inability to pay for food, housing, or basic necessities for 3 months or longer; (b) serious problems at work or loss of job; (c) serious family problems; (d) providing care for a close family member or friend with a serious illness; (e) legal problems; and (f) losing someone close due to accidental death, murder, or suicide.

To examine the relationship between PTSD trajectory group membership and PTSD diagnostic criteria, enrollees were categorized as to whether they met the DSM-IV-TR diagnostic criteria for all three symptom clusters (endorsed at least one reexperiencing symptom, three avoidance symptoms, and two hyperarousal symptoms as moderately or higher) at W1 without the addition of a cutoff score. The $D S M-I V$-TR symptom cluster criteria for PTSD has been used in previous Registry studies with and without an added criterion that PCL scores exceed a specific threshold (Digrande et al., 2008).

\section{Data Analysis}

We used group-based trajectory modeling to identify groups of enrollees with a similar pattern or trajectory of change in PCL score over time (Andruff, Carraro, Thompson, Gaudreau, \& Louvet 2009; Nagin, 2005). Using the PROC TRAJ macro (Jones, Nagin, \& Roeder, 2001) in SAS (Version 9.2, SAS Institute Inc., Cary, NC) with a censored normal distribution, we began with a single class model and added classes one at a time to examine improvements in model fit. We compared sample size-adjusted Bayesian information criterion (SSA-BIC) values between each model and the one preceding it. The decision to include additional groups was made based on a combination of SSA-BIC values, group sizes, and average posterior probabilities (Andruff et al., 2009; Nagin, 2005). Posterior probabilities measure individuals' likelihood of membership in each of the model's trajectory groups. Enrollees were assigned to the group for which their probability of membership was greatest (Nagin, 2005). The final model was selected based on parsimony, interpretability, and knowledge of our sample (Andruff et al., 2009; Nagin, 2005). Preliminary analyses revealed the presence of two pairs of groups with similar intercepts, but distinctly different trajectories over time. We calculated odds ratios and $95 \%$ confidence intervals using multivariable logistic regression to compare both pairs of groups. Regression analyses included covariates significant at the bivariate level using a $\chi^{2}$ test of independence $(p<.05)$. Subjects missing 


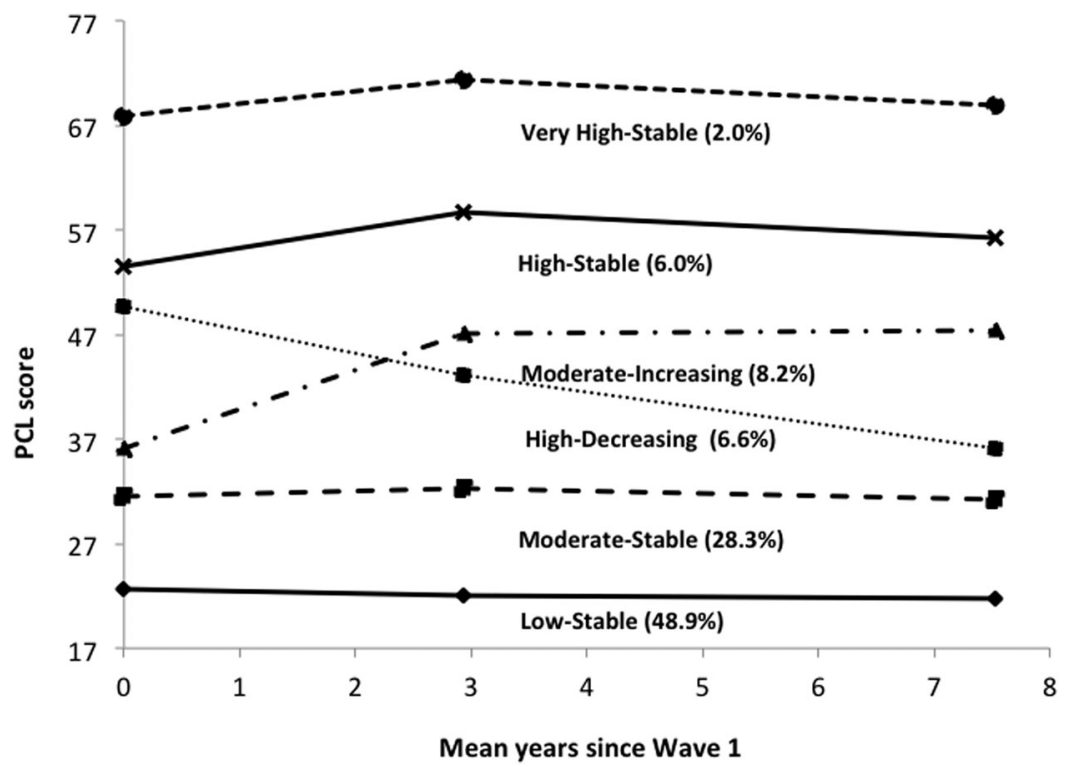

Figure 1. $N=17,062$. Trajectories of PTSD Checklist scores among area workers/residents in the World Trade Center Health Registry, $2003-2012$.

relevant independent variables were excluded from multivariable regression analyses comparing the moderate $(n=422)$ and high groups $(n=216)$. Bivariate analyses were also used to describe the association between quality of life and selected trajectory groups. All analyses were conducted using SAS (Version 9.2).

\section{Results}

A model with six trajectory groups (SSA-BIC $=-179,916.0$ ) best described PCL scores over the study period in our sample. The 5-group model had a higher absolute SSA-BIC $(-180,281.3)$ and forced consistently higher scores into a group with consistently lower scores; therefore, it did not accurately represent the distribution of scores in this sample. Allowing these two groups to form separate trajectories was given priority over a more-balanced solution in which each group contained at least $5 \%$ of the sample. Although the absolute value of the SSA-BIC was lower in models with seven and eight groups
$(-179,455.4$ and $-179,082.9$, respectively), these models lacked parsimony and interpretability. Moreover, each contained more than one group with less than $5 \%$ of the population and did not provide additional insight into the sample.

A description of our study population is provided in Table 1 . Figure 1 shows the pattern of trajectories and Table 2 provides the proportion of enrollees, average posterior probability, mean PCL score, and proportion of enrollees with probable PTSD (using a PCL cutoff of 44) at each wave for each group. Groups were labeled according to their intercept (low, moderate, high, or very high) and trajectory pattern (stable, increasing, or decreasing). The largest proportion (48.9\%) was assigned to a low-stable group, $28.3 \%$ to a moderate-stable group, $8.2 \%$ to a moderate-increasing group, $6.0 \%$ to a high-stable group, $6.6 \%$ to a high-decreasing group, and $2.0 \%$ to a very high-stable group.

Table 3 shows the frequency of five WTC-related exposures in the study population and within each of the six PTSD

Table 2

Trajectories of PTSD: Mean PCL Score and PTSD Prevalence at Waves 1, 2, 3 With Average Posterior Probabilities

\begin{tabular}{|c|c|c|c|c|c|c|c|c|c|c|c|}
\hline \multirow[b]{2}{*}{ Group } & \multirow[b]{2}{*}{$\begin{array}{c}\text { Total } \\
n\end{array}$} & \multirow{2}{*}{$\begin{array}{c}\text { Average } \\
\text { posterior } \\
\text { probability }(\%)\end{array}$} & \multicolumn{3}{|c|}{ Wave 1 PCL } & \multicolumn{3}{|c|}{ Wave 2 PCL } & \multicolumn{3}{|c|}{ Wave 3 PCL } \\
\hline & & & $M$ & $S D$ & $\begin{array}{c}\% \\
\text { PTSD }\end{array}$ & $M$ & $S D$ & $\begin{array}{c}\% \\
\text { PTSD }\end{array}$ & $M$ & $S D$ & $\begin{array}{c}\% \\
\text { PTSD }\end{array}$ \\
\hline Low-stable & 8,349 & 91.0 & 2.53 & 4.62 & 0.1 & 21.80 & 4.11 & 0.02 & 21.56 & 4.21 & 0.05 \\
\hline Mod-stable & 4,836 & 80.1 & 32.11 & 6.81 & 5.4 & 33.01 & 6.80 & 7.0 & 31.80 & 6.92 & 5.4 \\
\hline Mod-increasing & 1,103 & 78.0 & 35.69 & 6.92 & 12.1 & 47.73 & 9.17 & 68.7 & 48.21 & 8.63 & 69.4 \\
\hline HI-stable & 1,021 & 85.1 & 53.75 & 8.64 & 88.3 & 58.90 & 8.48 & 96.1 & 56.46 & 9.26 & 92.1 \\
\hline HI-decreasing & 1,117 & 77.4 & 51.09 & 7.11 & 88.7 & 43.24 & 9.11 & 48.7 & 35.86 & 7.64 & 16.6 \\
\hline Very HI-stable & 336 & 89.3 & 68.50 & 8.67 & 100 & 71.78 & 7.27 & 100 & 69.06 & 8.84 & 99.4 \\
\hline
\end{tabular}

Note. $N=17,062$. PTSD $=$ posttraumatic stress disorder; PCL $=$ PTSD Checklist. Cutoff for PTSD is PCL $\geq 44$. Mod $=$ moderate; HI $=$ high. 
Table 3

Prevalence of WTC-Related Exposures Among Area Residents/Workers by Six PTSD Trajectory Groups

\begin{tabular}{|c|c|c|c|c|c|c|c|c|c|c|c|c|c|c|}
\hline \multirow[b]{2}{*}{ Variable } & \multicolumn{2}{|c|}{$\begin{array}{c}\text { Total } \\
(N=17,062)\end{array}$} & \multicolumn{2}{|c|}{$\begin{array}{l}\text { Low-stable } \\
(n=8,349)\end{array}$} & \multicolumn{2}{|c|}{$\begin{array}{l}\text { Mod-stable } \\
(n=4,836)\end{array}$} & \multicolumn{2}{|c|}{$\begin{array}{l}\text { Mod-increasing } \\
\quad(n=1,403)\end{array}$} & \multicolumn{2}{|c|}{$\begin{array}{l}\text { HI-stable } \\
(n=1,021)\end{array}$} & \multicolumn{2}{|c|}{$\begin{array}{l}\text { HI-decreasing } \\
(n=1,117)\end{array}$} & \multicolumn{2}{|c|}{$\begin{array}{l}\text { Very HI-stable } \\
\quad(n=336)\end{array}$} \\
\hline & $n$ & $\%$ & $n$ & $\%$ & $n$ & $\%$ & $n$ & $\%$ & $n$ & $\%$ & $n$ & $\%$ & $n$ & $\%$ \\
\hline 9/11-related job loss & 1,529 & 9.0 & 399 & 4.8 & 378 & 7.8 & 180 & 12.8 & 248 & 24.3 & 185 & 16.6 & 139 & $\overline{41.4}$ \\
\hline Witnessed $3+9 / 11$ events & 8,004 & 46.9 & 3,043 & 36.5 & 2,427 & 50.2 & 865 & 61.7 & 731 & 71.6 & 677 & 60.6 & 261 & 77.7 \\
\hline Threat of 9/11 injury/death & 11,601 & 68.0 & 4,637 & 55.5 & 3,638 & 75.2 & 1,163 & 82.9 & 914 & 89.5 & 934 & 83.6 & 315 & 93.8 \\
\hline 9/11-related bereavement & 9,172 & 53.8 & 3,995 & 47.9 & 2,672 & 55.3 & 913 & 65.1 & 709 & 69.4 & 641 & 57.4 & 242 & 72.0 \\
\hline Sustained $9 / 11$ injury & 1,963 & 11.5 & 449 & 5.4 & 551 & 11.4 & 234 & 16.7 & 319 & 31.2 & 244 & 21.8 & 166 & 49.4 \\
\hline
\end{tabular}

Note. $N=17,062$. Pairwise comparisons for the moderate-stable versus moderate-increasing and high-stable versus high-decreasing groups were significant for all WTC-related exposures $(p<.001)$ using $\chi^{2}$ test of independence. WTC $=$ World Trade Center; PTSD $=$ posttraumatic stress disorder; Mod $=$ moderate; HI $=$ high

trajectory groups. The proportions of enrollees experiencing each WTC-related exposure were smallest in the low-stable and moderate-stable groups and largest in the high-increasing and very high-stable groups. Pairwise comparisons for the moderate-stable versus moderate-increasing and high-stable versus high-decreasing groups were significant for all WTCrelated exposures using $\chi^{2}$ test of independence $(p<.001)$.

Our analysis produced two pairs of trajectory groups with similar intercepts at W1, but whose trajectory patterns diverged significantly over the remainder of the study period. Enrollees in the moderate pair had mean PCL scores at W1 below the PTSD cutoff of 44 (35.69, $S D=6.92$ and 32.11, $S D=6.81$, respectively; Figure 1 and Table 2), $22.5 \%$ of whom had mean PCL scores that increased over time (moderate-increasing), while the remainder stayed the same (moderate-stable). Enrollees in the high pair had intercepts at W1 well above the PTSD cutoff $(53.75, S D=8.64$ and 51.09, $S D=70.11$, respectively), $52.4 \%$ of whom had scores that decreased over time (high-decreasing), whereas the remainder had persistently high scores (high-stable). To understand factors associated with the divergence observed in each pair, we compared the moderate-increasing group to the moderate-stable group and the high-stable group to the high-decreasing group in separate multivariable regressions. Gender, race/ethnicity, age, and income were not significantly associated with group membership in either set of bivariate analyses; employment at W1, DSM-IV-TR symptom cluster criteria, and 9/11related job loss were not significantly associated in bivariate analyses comparing the high-stable to the high-decreasing group.

With the exception of pre-9/11 mental health diagnosis, the adjusted odds of being in the moderate-increasing group compared to the moderate-stable group were significantly elevated for all other demographic and psychosocial factors, notably for those who had 9/11-related job loss or met all three $D S M-I V-T R$ symptom cluster criteria; and for all 9/11-related exposures, notably among enrollees who had witnessed three or more horrific events or were bereft (Table 4). When compared to enrollees in the UMHN-/MHT - group, enrollees in the $\mathrm{UMHN}+/ \mathrm{MHT}+$ group were more likely to be in the moderateincreasing group, as were those in the UMHN+/MHT - and UMHN-/MHT+ groups.
When compared to the high-decreasing group, the odds of being in the high-stable group were significantly elevated among enrollees who did not graduate college, had low social integration, witnessed three or more horrific events, were bereft, or sustained an injury (Table 4). The odds of being in the high-stable group were also significantly elevated among enrollees in the $\mathrm{UMHN}+/ \mathrm{MHT}+, \mathrm{UMHN}+/ \mathrm{MHT}-$, and $\mathrm{UMHN}-/ \mathrm{MHT}+$ groups when compared to the UMHN-/MHT- group (Table 4).

Poorer quality of life was reported by enrollees in the moderate-increasing and high-stable groups compared to the moderate-stable and high-decreasing groups, respectively $(p<$ .001; Table 5). Proportions of enrollees in both the moderateincreasing and high-stable groups reporting impaired quality of life were 2-3 times larger than the proportions observed in the moderate-stable and high-decreasing groups, respectively.

\section{Discussion}

We described empirical trajectories of change in PTSD symptoms and evaluated factors associated with change in PTSD symptoms over time using group-based trajectory modeling. We found a substantial burden of PTSD among directly exposed area residents/workers in the vicinity of the WTC disaster, $16.2 \%$ of whom reported symptoms of PTSD that either persisted throughout or worsened from W1 to W3. In fact, those with the highest levels of exposure, including sustaining an injury, fearing for one's safety, low social integration, 9/11-related job loss, and unemployment, faced the greatest risk of continuing to experience life-limiting PTSD symptoms. These findings are consistent with Maslow et al.'s (2015) study of RRW enrolled in the Registry in which these same factors were associated with higher likelihood of membership in a trajectory that worsened over time rather than in one that remained stable or improved.

In our study population, we selected a parsimonious and interpretable model with six distinct groups to best summarize PTSD trajectories 10-11 years post-9/11. We identified groups with persistently low PCL scores, commonly described as resilient/resistant; persistently high scores, described as chronic; declining scores, described as recovered; and increasing scores, described as delayed-onset (Bonanno et al., 
Table 4

Adjusted Odds Ratios ${ }^{a}$ and 95\% Confidence Intervals for Selected Characteristics and Trajectory Group Membership

\begin{tabular}{|c|c|c|c|c|}
\hline \multirow[b]{2}{*}{ Variable } & \multicolumn{2}{|c|}{$\begin{array}{l}\text { Moderate-increasing } \\
\text { vs. moderate-stable }\end{array}$} & \multicolumn{2}{|c|}{$\begin{array}{l}\text { High-stable vs. } \\
\text { high-decreasing }\end{array}$} \\
\hline & $O R$ & $95 \% \mathrm{CI}$ & $O R$ & $95 \% \mathrm{CI}$ \\
\hline \multicolumn{5}{|c|}{ Wave 1 college graduate } \\
\hline No & 1.31 & {$[1.14,1.51]$} & 1.30 & {$[1.07,1.58]$} \\
\hline \multicolumn{5}{|l|}{ Wave 1 employed $^{\mathrm{b}}$} \\
\hline No & 1.39 & {$[1.15,1.68]$} & - & - \\
\hline \multicolumn{5}{|c|}{ Wave 2 social integration } \\
\hline Low & 2.18 & {$[1.73,2.75]$} & 2.23 & {$[1.65,3.02]$} \\
\hline \multicolumn{5}{|c|}{ Wave 2 unmet MH need, service use } \\
\hline UMHN+ MHT+ & 4.37 & {$[3.04,6.26]$} & 3.42 & {$[2.29,5.11]$} \\
\hline UMHN+ MHT- & 3.32 & {$[2.38,4.64]$} & 2.72 & {$[1.86,3.98]$} \\
\hline UMHN- MHT+ & 1.88 & {$[1.63,2.18]$} & 2.24 & {$[1.81,2.78]$} \\
\hline \multicolumn{5}{|c|}{ Pre-9/11 mental health diagnosis ${ }^{c}$} \\
\hline Yes & 1.07 & {$[0.89,1.28]$} & 0.80 & {$[0.62,1.03]$} \\
\hline \multicolumn{5}{|c|}{ Wave 1 met criteria for full PTSD ${ }^{b}$} \\
\hline Yes & 1.81 & {$[1.52,2.17]$} & - & - \\
\hline \multicolumn{5}{|l|}{ 9/11-related job loss ${ }^{b}$} \\
\hline Yes & 1.41 & {$[1.14,1.75]$} & - & - \\
\hline \multicolumn{5}{|c|}{ Witnessed $3+9 / 11$ events } \\
\hline Yes & 1.50 & {$[1.31,1.72]$} & 1.43 & {$[1.16,1.76]$} \\
\hline \multicolumn{5}{|c|}{ Threat of 9/11 injury/death } \\
\hline Yes & 1.44 & {$[1.21,1.71]$} & 1.39 & {$[1.03,1.87]$} \\
\hline \multicolumn{5}{|c|}{ 9/11-related bereavement } \\
\hline Yes & 1.53 & {$[1.33,1.75]$} & 1.45 & {$[1.18,1.77]$} \\
\hline \multicolumn{5}{|l|}{ Sustained $9 / 11$ injury } \\
\hline Yes & 1.34 & {$[1.12,1.61]$} & 1.45 & {$[1.16,1.80]$} \\
\hline
\end{tabular}

Note. $N=17,062$. UMHN+ $=$ reported unmet mental healthcare need; UMHN- $=$ did not report unmet mental healthcare need; MHT $+=$ received mental health treatment; MHT - = did not receive mental health treatment; PTSD = posttraumatic stress disorder.

${ }^{a}$ Additionally adjusted for mode of enrollment and survey mode (mail, web, telephone) at Waves 2 and $3 .{ }^{b}$ Not included in the high-stable versus high-decreasing regression model due to a lack of significance at the bivariate level. ${ }^{c}$ Posttraumatic stress disorder, depression, and/or other anxiety disorder.

2012; de-Roon-Cassini et al., 2010; Pietrzak et al., 2014). As expected and consistent with previous studies, including the Registry's RRW study (Maslow et al., 2015), the largest proportions were in groups with resilient/resistant trajectories (lowstable and moderate-stable; $77.2 \%$ ) and the smallest proportions in groups with chronic trajectories (high-stable and very highstable; $8.0 \%$ ). Our finding of six groups is comparable with Pietrzak et al. (2014), who found six similar trajectory groups among nontraditional WTC responders. Previous studies, including an earlier Registry study (Brackbill et al., 2009) and two other longitudinal studies of NYC residents (Boscarino \& Adams, 2009; Neria et al., 2010) have described four categories of change in PTSD over time based on dichotomous PTSD status at each of two time points; without a third time point, these previous studies could not model individual score trajectories as was done in both our current study and the Pietrzak et al. study.
Clinical assessments or diagnostic interviews are not a practical means of identifying persons likely in need of services following a disaster; a relatively simple screen with good diagnostic efficiency, like the PCL, can therefore be a crucial component of postdisaster needs assessments. The PCL has been used in multiple ways to assess PTSD status, either based on a cutoff score, the DSM-IV-TR symptom cluster criteria, or a combination of the two. A cutoff score treats all symptoms equally and may not be the best approach, as symptom patterns or clusters may differ over the course of PTSD, for example, in our study population among those with delayed-onset PTSD. Our findings suggested that the choice of screening criteria and frequency of follow-up assessments be carefully designed to reflect the expected course of psychopathology long after the occurrence of the traumatic event. Further examination of symptom clusters in this manner is an important area for future research. 
Table 5

Quality of Life at Wave 3 and Trajectory Group Membership

\begin{tabular}{|c|c|c|c|c|c|c|c|c|}
\hline \multirow[b]{2}{*}{ Variable } & \multicolumn{2}{|c|}{$\begin{array}{c}\text { Moderate-increasing } \\
\quad n=1,403\end{array}$} & \multicolumn{2}{|c|}{$\begin{array}{c}\text { Moderate-stable } \\
n=4,836\end{array}$} & \multicolumn{2}{|c|}{$\begin{array}{c}\text { High-stable } \\
n=1,021\end{array}$} & \multicolumn{2}{|c|}{$\begin{array}{c}\text { High-decreasing } \\
n=1,117\end{array}$} \\
\hline & $n$ & $\%$ & $n$ & $\%$ & $n$ & $\%$ & $n$ & $\%$ \\
\hline \multicolumn{9}{|l|}{ Life satisfaction } \\
\hline Very dissatisfied or dissatisfied & 518 & 37.4 & 790 & 16.4 & 484 & 48.2 & 267 & 24.2 \\
\hline \multicolumn{9}{|l|}{ General health } \\
\hline Fair or poor & 604 & 43.3 & 1,067 & 22.2 & 611 & 60.4 & 378 & 34.2 \\
\hline \multicolumn{9}{|l|}{ Poor mental health days } \\
\hline$\geq 14$ & 670 & 48.3 & 951 & 19.9 & 636 & 63.2 & 325 & 29.6 \\
\hline \multicolumn{9}{|l|}{ PTSD-related difficulty } \\
\hline At least some difficulty & 1,148 & 82.3 & 2,038 & 42.8 & 915 & 90.3 & 642 & 58.3 \\
\hline \multicolumn{9}{|l|}{ Life stressors over last 12 months $^{\mathrm{a}}$} \\
\hline $3+$ & 147 & 10.6 & 163 & 3.4 & 133 & 13.1 & 64 & 5.8 \\
\hline $1-2$ & 536 & 38.5 & 1,470 & 30.6 & 402 & 39.7 & 353 & 31.8 \\
\hline None & 708 & 50.9 & 3,176 & 66.0 & 478 & 47.2 & 692 & 62.4 \\
\hline
\end{tabular}

Note. PTSD = posttraumatic stress disorder. Pairwise comparisons for the moderate-stable versus moderate-increasing and high-stable versus high-decreasing groups were significant for all quality of life measures $(p<.001)$.

${ }^{a}$ Inability to pay for food, housing or basic necessities for 3 months or longer, serious problems at work or job loss, serious family problems, providing care for a close family member or friend with a serious illness, legal problems, and/or losing someone close due to accidental death, murder, or suicide.

The increased likelihood of having chronic or worsening PTSD among persons in this study reporting low social integration is important to note, as social isolation is considered a modifiable risk factor. Persons reporting low levels of social integration are likely to be socially isolated, which has been shown to be associated with depression, anxiety, and other mental health disorders (Chou et al., 2011). Additionally, social integration and social ties are positively related to health, buffering the negative effects of stress exposures on physical and mental health (Thoits, 2011).

Having PTSD symptoms that worsened rather than remained stable over time was associated with unemployment at W1 and 9/11-related job loss. Employment is related to several factors associated with onset and worsening of PTSD. For many individuals, unemployment leads to a loss of social and emotional support from their colleagues who shared their $9 / 11$ exposure and experiences and were an integral part of their post-9/11 coping strategies (North, Barney, \& Pollio, 2015). Additionally, loss of employment represents changes in socioeconomic status, including reduced access to financial resources like pensions, disability benefits, and health insurance (Beaton, Murphy, Pike, \& Corneil, 1997; Robinaugh et al., 2011).

We found that compared to those reporting no unmet mental health care need or mental health treatment, enrollees with $\mathrm{UMHN}+/ \mathrm{MHT}+$, $\mathrm{UMHN}+/ \mathrm{MHT}-$, or $\mathrm{UMHN}-/ \mathrm{MHT}+$ were significantly more likely to have a PCL trajectory that worsened or remained high over time rather than remaining stable or decreasing. The probability of having a worsening or high PCL trajectory was highest among those reporting simultaneous unmet need and receipt of mental health treatment (UMHN+/MHT+). Individuals with chronic and delayed-onset PTSD may have experienced difficulty accessing mental health care, felt their needs were not being met even when receiving care, or experienced delays in accessing treatment, which may have contributed to the long-term PTSD observed in this study. It is likely that area residents/workers with PTSD may have received care for physical symptoms well before emotional symptoms, as many have comorbid physical health problems likely resulting from either their $9 / 11$ exposure and/or somatization (Nair et al., 2012).

Although treatment, but not monitoring, services for certifiable 9/11-related conditions became available after 9/11 for area residents/workers at a federally funded health program (WTC Health Program for Survivors), previous Registry studies have shown that many individuals eligible for this program had not utilized services prior to a Registry intervention, largely because they were unaware of their eligibility for this program or were not referred to the program by their primary care provider (Welch et al., 2012, 2014). This emphasizes the need to train community-based medical providers to recognize symptoms of and risk factors for PTSD and increase their knowledge and awareness of available postdisaster resources to promote timely referrals for those with current, new-onset, or worsening PTSD symptoms.

This study had several limitations. All data in this study were self-reported. In particular, we relied on a self-administered checklist, rather than a clinical interview, to determine the severity of PTSD symptoms. There were three assessments over a 9-year follow-up period, which may have been insufficient to identify some trends in PCL scores over the study period; we plan to replicate this analysis in the future with the addition of a fourth assessment. Additional limitations included loss to follow-up and differential rates of participation among those with and without PTSD at each survey wave. Enrollees excluded for not having completed all three waves were more likely to have had PTSD at W1; as such, our findings may have underestimated the proportions of enrollees with chronic and/or resolved PTSD. Additional analyses revealed no substantial 
impact of potentially nonrandom patterns of missing data or the exclusion of enrollees not completing all three waves. Data on exposure to $9 / 11$ were collected up to 6 years after the event and were subject to recall bias. Our measure of social integration was limited to four items and may not have included potential sources of integration available to our population. Finally, our findings may not be generalizable because they are from a volunteer sample.

This study had several strengths, including its large sample size and data on various 9/11 exposures, unmet mental health care need, mental health treatment, and quality of life. In addition, our data spanned a period of 8 to 9 years and were collected up to 11 years postevent, enabling us to extend the period of time observed in prior studies and allowing for a wider timeframe in which to observe emerging psychopathology.

Our findings indicated that $8.0 \%$ of area residents/workers enrolled in the Registry were following a trajectory consistent with chronic PTSD that had persisted over 8 to 9 years, whereas another $8.2 \%$ were following a trajectory indicating delayedonset PTSD symptoms. Based on an estimated 319,000 area residents/workers directly exposed to the 9/11 attacks (Murphy et al., 2007), over 25,000 individuals are projected to be suffering from chronic PTSD and an additional 25,000 are likely to have delayed-onset PTSD. The projected high burden of PTSD and impaired quality of life among a disaster-exposed population suggests a need for immediate and periodic monitoring of mental health symptoms among all disaster-exposed persons. Moreover, these findings highlight important PTSD risk factors for consideration following a large-scale traumatic event, including traumatic exposures and social and economic risk factors such as event-related injury, bereavement, job loss, and low social integration, which are important several years postevent in addition to being relevant in the event's immediate aftermath.

\section{References}

Adams, R. E., \& Boscarino, J. A. (2006). Predictors of PTSD and delayed PTSD after disaster: The impact of exposure and psychosocial resources. Journal of Nervous and Mental Disease, 194, 485-493. doi:10.1097/01.nmd.0000228503.95503.e9

American Psychiatric Association. (2000). Diagnostic and statistical manual of mental disorders (4th ed., text rev.). Washington, DC: Author.

Andruff, H., Carraro, N., Thompson, A., Gaudreau, P., \& Louvet B. (2009). Latent class growth modelling: A tutorial. Tutorials in Quantitative Methods for Psychology, 5, 11-24.

Beaton, R. D., Murphy, S. A., Pike, K. C., \& Corneil, W. (1997). Social support and network conflict in firefighters and paramedics. Western Journal of Nursing Research, 19, 297-313. doi:10.1177/019394599701900303

Blanchard, E. B., Jones-Alexander, J., Buckley, T. C., \& Forneris, C. A. (1996). Psychometric properties of the PTSD Checklist (PCL). Behaviour Research and Therapy, 34, 669-673. doi:10.1016/0005-7967(96)00033-2

Bonanno, G. A., Mancini, A. D., Horton, J. L., Powell, T. M., Leardmann, C. A., Boyko, E. J., \& Smith, T. C. (2012). Trajectories of trauma symptoms and resilience in deployed U.S. military service members:
Prospective cohort study. The British Journal of Psychiatry, 200, 317-323. doi:10.1192/bjp.bp.111.096552

Boscarino, J. A., \& Adams, R. E. (2009). PTSD onset and course following the World Trade Center disaster: Findings and implications for future research. Social Psychiatry and Psychiatric Epidemiology, 44, 887-898. doi:10.1007/s00127-009-0011-y

Brackbill, R. M., Hadler, J. L., DiGrande, L., Ekenga, C. C., Farfel, M. R., Friedman, S., \& Thorpe, L. E. (2009). Asthma and posttraumatic stress symptoms 5 to 6 years following exposure to the World Trade Center terrorist attack. Journal of the American Medical Association, 302, 502-516. doi:10.1001/jama.2009.1121

Chou, K. L., Liang, K., \& Sareen, J. (2011). The association between social isolation and DSM-IV mood, anxiety, and substance use disorders: wave 2 of the National Epidemiologic Survey on Alcohol and Related Conditions. Journal of Clinical Psychiatry, 72, 1468-1476. doi:10.4088/JCP.10m06019gry

deRoon-Cassini, T. A., Mancini, A. D., Rusch, M. D., \& Bonanno, G. A. (2010). Psychopathology and resilience following traumatic injury: A latent growth mixture model analysis. Rehabilitation Psychology, 55, 1-11. doi:10.1037/a0018601

DiGrande, L., Perrin, M. A., Thorpe, L. E., Thalji, L., Murphy, J., Wu, D., \& Brackbill, R. M. (2008). Posttraumatic stress symptoms, PTSD, and risk factors among lower Manhattan residents 2-3 years after the September 11, 2001 terrorist attacks. Journal of Traumatic Stress, 21, 264-273. doi: $10.1002 /$ jts. 20345

Farfel, M., DiGrande, L., Brackbill, R., Prann, A., Cone, J., Friedman, S., \& Thorpe, L. (2008). An overview of 9/11 experiences and respiratory and mental health conditions among World Trade Center Health Registry enrollees. Journal of Urban Health, 85, 880-909. doi:10.1007/s11524-0089317-4

Galea, S., Ahern, J., Tracy, M., Hubbard, A., Cerda, M., Goldmann, E., \& Vlahov, D. (2008). Longitudinal determinants of posttraumatic stress in a population-based cohort study. Epidemiology, 19, 47-54. doi:10.1097/EDE.0b013e31815c1dbf

Hobfoll, S. E., Mancini, A. D., Hall, B. J., Canetti, D., \& Bonanno, G. A. (2011). The limits of resilience: Distress following chronic political violence among Palestinians. Social Science \& Medicine, 72, 1400-1408. doi:10.1016/j.socscimed.2011.02.022

Jones, B. L., Nagin, D. S., \& Roeder, K. (2001). A SAS procedure based on mixture models for estimating developmental trajectories. Sociological Methods \& Research, 29, 374-393. doi:10.1177/0165025409343765

Maslow, C. B., Caramanica, K., Welch, A. E., Stellman, S. D., Brackbill, R. M., \& Farfel, M. R. (2015). Trajectories of scores on a screening instrument for PTSD among World Trade Center rescue, recovery, and clean-up workers. Journal of Traumatic Stress, 28, 198-205. doi:10.1002/jts.22011

Murphy, J., Brackbill, R. M., Thalji, L., Dolan, M., Pulliam, P., \& Walker, D. J. (2007). Measuring and maximizing coverage in the World Trade Center Health Registry. Statistics in Medicine, 26, 1688-1701. doi:10.1002/sim.2806

Nagin, D. S. (2005). Group-based modeling of development. Cambridge, MA: Harvard University Press.

Nair, H. P., Ekenga, C. C., Cone, J. E., Brackbill, R. M., Farfel, M. R., \& Stellman, S. D. (2012). Co-occurring lower respiratory symptoms and posttraumatic stress disorder 5 to 6 years after the World Trade Center terrorist attack. American Journal of Public Health, 102, 1964-1973. doi:10.2105/AJPH.2012.300690

Neria, Y., Olfson, M., Gameroff, M. J., DiGrande, L., Wickramaratne, P., Gross, R., \& Weissman, M. M. (2010). Long-term course of probable PTSD after the 9/11 attacks: A study in urban primary care. Journal of Traumatic Stress, 23, 474-482. doi:10.1002/jts.20544 
Norris, F. H., Tracy, M., \& Galea, S. (2009). Looking for resilience: Understanding the longitudinal trajectories of responses to stress. Social Science \& Medicine, 68, 2190-2198. doi:10.1016/j.socscimed.2009.03.043

North, C. S., Barney, C. J., \& Pollio, D. E. (2015). A focus group study of the impact of trauma exposure in the 9/11 terrorist attacks. Social Psychiatry and Psychiatric Epidemiology, 50, 569-578. doi:10.1007/s00127-014-0970-5

Perlman, S. E., Friedman, S., Galea, S., Nair, H. P., Eros-Sarnyai, M., Stellman, S. D., \& Greene, C. M. (2011). Short-term and medium-term health effects of 9/11. The Lancet, 378, 925-934. doi:10.1016/S0140-6736(11)60967-7

Pietrzak, R. H., Feder, A., Singh, R., Schechter, C. B., Bromet, E. J., Katz, C. L., \& Southwick, S. M. (2014). Trajectories of PTSD risk and resilience in World Trade Center responders: An 8-year prospective cohort study. Psychological Medicine, 44, 205-219. doi:10.1017/S0033291713000597

Robinaugh, D. J., Marques, L., Traeger, L. N., Marks, E. H., Sung, S. C., Gayle Beck, J., \& Simon, N. M. (2011). Understanding the relationship of perceived social support to post-trauma cognitions and posttraumatic stress disorder. Journal of Anxiety Disorders, 25, 1072-1078. doi:10.1016/j.janxdis.2011.07.004

Steenkamp, M. M., Dickstein, B. D., Salters-Pedneault, K., Hofmann, S. G., \& Litz, B. T. (2012). Trajectories of PTSD symptoms following sexual assault:
Is resilience the modal outcome? Journal of Traumatic Stress, 25, 469-474. doi: $10.1002 /$ jts. 21718

Thoits, P. A. (2011). Mechanisms linking social ties and support to physical and mental health. Journal of Health and Social Behavior, 52, 145-161. doi:10.1177/0022146510395592

Ventureyra, V. A., Yao, S. N., Cottraux, J., Note, I., \& DeMey-Guillard, C. (2002). The validation of the Posttraumatic Stress Disorder Checklist Scale in posttraumatic stress disorder and nonclinical subjects. Psychotherapy and Psychosomatics, 71, 47-53.

Weathers, F.W., Litz, B.T., Herman, D.S., Huska, J.A., \& Keane, T.M. (1993). The PTSD Checklist (PCL): Reliability, validity, and diagnostic utility. Paper presented at the 9th Annual Conference of the ISTSS, San Antonio.

Welch, A. E., Caramanica, K., Debchoudhury, I., Pulizzi, A., Farfel, M. R., Stellman, S. D., \& Cone, J. E. (2012). A qualitative examination of health and health care utilization after the September 11th terror attacks among World Trade Center Health Registry enrollees. BMC Public Health, 12, 721. doi:10.1186/1471-2458-12-721

Welch, A. E., Debchoudhury, I., Jordan, H., Petrsoric, L., Farfel, M., \& Cone, J. (2014). Translating research into action: An evaluation of the World Trade Center Health Registry's Treatment Referral Program. Disaster Health, 2, 97-105. doi:10.4161/dish.28219 